\title{
YouTube en la gestión de la comunicación de museos e instituciones culturales: propuesta para extrapolar un uso comunicacional de estas herramientas a pequeñas instituciones culturales
}

\author{
Georgina Marcelino Mercedes, Universidad Camilo José Cela, España
}

\begin{abstract}
Resumen: YouTube sitio web para publicar y compartir videos se ha convertido en una plataforma fundamental de interactividad entre los usuarios en la era de internet, a la vez que en una potente herramienta de divulgación comercial para marcas, empresas e instituciones. Bajo la preeminencia de las redes sociales, el uso proliferado de smartphones y demás dispositivos móviles con cámaras de video integradas y capacidad de conexión a internet, así como el nacimiento en los últimos cinco años de nuevas redes sociales basadas en imágenes en movimiento como Vine o Instagram, se hace necesario más que nunca adoptar al video online como parte fundamental de una estrategia de comunicación efectiva. Analizamos las claves del uso de YouTube en la comunicación de Museos e Instituciones Culturales de gran envergadura, como parte importante de su estrategia de comunicación, para difundir material cultural e institucional, como herramienta de documentación de acceso público y como canal interactivo, con el fin de presentar una propuesta teórica extrapolable a instituciones culturales más pequeñas y de alcance local, considerando las posibilidades que ofrece YouTube como parte de un plan de comunicación adaptado a una nueva tipología de público cultural.
\end{abstract}

Palabras clave: youtube, museos, comunicación cultural, video

\begin{abstract}
YouTube is a web site to publish and share videos has become an important interaction platform between users in the Internet age, and simultaneously a powerful tool for brands, companies and institutions. We live in a new Social Era with the increasing use of smartphones and other mobile devices with integrated video cameras, and additionally the emergence in the last five years of new social networks based on moving images as Vine or Instagram, it is necessary more than ever to take in consideration the online video as a fundamental part of an effective communication strategy. We want to analyze the use of YouTube in Museums and cultural institutions as an important part of its communication strategy, such as documentation tool and as an interactive public access channel, in order to present our theoretical proposal of use of YouTube extrapolated to smaller cultural institutions, considering the possibilities offered by YouTube as part of a communication plan focused in a new kind of cultural visitors.
\end{abstract}

Keywords: YouTube, Museums, Cultural Communication, Video

\section{Introducción}

Y ouTube es más que un portal de entretenimiento, ha trascendido además, como medio de comunicación de gran relevancia social, y no sólo por su alcance sino también por permitir la difusión de contenidos de forma libre, democrática y gratuita. Nos proponemos descubrir lo que distingue a YouTube de los medios de comunicación tradicionales y las características que le permiten sobresalir como herramienta audiovisual en línea superando a los tradicionales servicios de video bajo demanda.

El presente artículo explora en una primera fase los momentos más relevantes de la evolución y desarrollo del sitio web de vídeos en línea YouTube, el de mayor éxito en las últimas décadas, hoy en día, una plataforma clave de interactividad entre los usuarios en la era de internet y también una potente herramienta de divulgación comercial para marcas, empresas e instituciones.

Analizaremos cómo se ha integrado YouTube en la gestión de la comunicación de museos e instituciones culturales, como parte importante de su estrategia de comunicación en internet, como herramienta de documentación de acceso público y como canal interactivo.

Revista Internacional de Cultura Visual

Volumen 2, Número $1<\mathrm{http}: / /$ sobreculturavisual.com>, ISSN 2530-4666

(C) Global Knowledge Academics. Georgina Marcelino Mercedes. Todos los derechos reservados.

Permisos: soporte@gkacademics.com

Republicado de Revista Internacional de la Imagen 2(1), 2015 (pp.21-29) 
Tras un vistazo inicial a los canales de YouTube de índole corporativa de varios museos de gran tamaño, distinguiremos las acciones más relevantes que estos realizan en YouTube para finalmente extraer un listado de puntos y acciones específicas que podrán ser puestas en práctica por instituciones culturales de menor envergadura o de carácter local, con el fin de presentar una propuesta teórica extrapolable a instituciones culturales, considerando las posibilidades que ofrece YouTube como parte de un plan de comunicación adaptado a una nueva tipología de público cultural.

Nuestra aportación final pasa a ser un breve apunte de recomendaciones que entendemos pueden enriquecer la estrategia de comunicación de instituciones culturales que están interesadas en aprovechar una herramienta como YouTube que es hoy es un elemento relevante entre las opciones de entretenimiento, información y educación de su público potencial.

\section{Qué es YouTube y cómo ha evolucionado su historia}

Hasta hace unas décadas habíamos podido apreciar cómo la producción y realización de videos noprofesionales a manos de individuos particulares se limitaba a los videos caseros de tema familiar, o al registro de algún acontecimiento de índole personal, una forma de inmortalizar momentos de gran importancia para este realizador amateur y su círculo cercano, sin embargo, como bien ha señalado Renó (2007), a partir del momento en que la tecnología ofreció nuevas herramientas de creación y edición a los usuarios, la producción de videos populares cobró una nueva fuerza, antes de esto la realización y la distribución de material audiovisual estaba en manos sólo de los profesionales.

El año 2005 marcó un antes y un después en la historia de la industria audiovisual cuando en febrero de ese mismo año surge de mano de tres antiguos empleados de Paypal: Chad Hurley, Steve Chen y Jawed Karim, el portal YouTube, (Lavado, 2010). YouTube es un sitio web de vídeos que permite a miles de millones de usuarios encontrar, ver y compartir videos originales, de forma gratuita. (YouTube, 2014)

Al 2005 podríamos considerarlo el año de la revolución del video, además del nacimiento de YouTube se suscitan otros acontecimientos relevantes en este campo; Yahoo Inc., lanza la primera versión de Yahoo Video y un servicio de videos musicales; las cadenas estadounidenses NBC y $\mathrm{CNN}$ incursionan en la transmisión de video y programas en tiempo real a través de la web, iTunes y AOL también ofrecerán video a partir de ese año, y es también a mediados de 2005 cuando como consecuencia de la popularización de los videos YouTube consigue la inyección de financiación que le permite duplicar el tráfico a 104 millones de páginas vistas (Polo Serrano, 2010), y este es sólo el primero de una serie de acontecimientos relevantes que convertirán a YouTube en el gran éxito de internet que es hoy en día. En 2006, YouTube es adquirido por Google por 1.650 millones de dólares, el equivalente a unos 1.300 millones de euros (El País, 2006), posteriormente, entre finales de 2009 y comienzos de 2010 YouTube rediseña su interfaz a una más intuitiva (Polo Serrano, 2010). Todo esto resulta en una serie de referencias que nos indican un monumental proceso de crecimiento en relativamente pocos años.

¿Por qué afirmamos con tanta seguridad que al hablar de YouTube hablamos de un portal de internet de gran éxito?, las estadísticas de YouTube (2014) nos ayudan a contestar esta pregunta, ya que, hoy en día más de mil millones de usuarios únicos visitan YouTube cada mes y está traducido a 61 idiomas. Sucesivamente, se ha convertido en el portal de videos más popular de la era de internet y el portal de internet más exitoso de la nueva generación, ganando el puesto del cuarto portal en línea con más tráfico en toda la historia de internet. (Cheng, Dale y Liu, 2007; Davidson et al., 2010), y todo esto que observamos ha sucedido en poco menos de una década.

El notable éxito y la popularización de YouTube lo ha llevado a transformarse en un sitio más social (Cheng, Dale, Liu. 2007), el usuario de YouTube puede comentar videos, calificarlos y compartirlos a través de redes sociales o en un mensaje de email. La capacidad, y diríamos, que incluso la intención de los usuarios de compartir vídeos de YouTube con otros en sus círculos sociales sugiere que el uso social de YouTube está influido por la interacción interpersonal del usuario con otros. (Haridakis y Hanson, 2009), es una herramienta en línea que como muchas otras de la nueva web social se retroalimenta de las interacciones sociales entre los individuos fuera de línea. 
El estudio investigativo que hicieran Cheng, Daley Liu (2007) determinó que música, entretenimiento y comedia son las tres categorías más representativas en las que se engloban los videos alojados en YouTube, podríamos incluso afirmar que son categorías de alguna manera relacionadas con gustos personales, que si bien, pueden disfrutarse en solitario, también cumplen con condiciones psicológicas y sociales para poder compartirse o ser compartidos. Otra particularidad que extraemos de las estadísticas publicadas por el propio portal es que al día de hoy alrededor del $40 \%$ del tiempo total de visualización de YouTube procede de dispositivos móviles (YouTube, 2014), hablamos claramente de un portal que no sólo ha nacido en la denominada «segunda ola de internet», sino, que además ha conseguido adaptarse a cada una de las nuevas fases de comportamiento e interacción que han se han originado con ésta, como por ejemplo, la proliferación del uso de teléfonos inteligentes y otros dispositivos móviles con conexión a internet.

Quizás, quien no sea usuario o visitante activo del portal YouTube podría no entender qué es lo que impulsa a los usuarios de este sitio a ver videos que en muchas ocasiones figuran con baja calidad audiovisual, reconocemos que, en términos generales, la utilidad y legitimidad de un medio de comunicación se evaluaría de acuerdo a la calidad de la información que este proporcione, pero, resulta algo distinto en el caso de YouTube, ¿por qué?, lo que sucede es que estos videos sirven a funciones sociales que no están necesariamente pareadas con su estética o nivel técnico (Lange, 2008); los usuarios que accedemos a los videos publicados en YouTube buscamos entretenernos, informarnos, divertirnos, culturizarnos o incluso estremecernos sentimentalmente, perseguimos un beneficio específico relacionado a la temática de estos videos y evaluamos los mismos en torno a cómo cumplen su cometido dejando sus especificaciones técnicas en un segundo plano.

YouTube también ha representado un cambio importante en la democratización de la información, antes de YouTube los productos culturales audiovisuales que ofrecía internet eran elitistas o filtrados por la élite, (Renó, 2007), era este grupo sociocultural el que de alguna manera decidía qué material audiovisual era apto para el consumo. YouTube, no distingue las clases sociales, en un espacio abierto donde podemos elegir libremente lo que consumimos, y más interesante aún, nos permite difundir material original que pueda ser consumido por otros receptores.

Uno de los más poderosos subproductos del uso de las tecnologías y las redes sociales es la creación de una narrativa personal que a su vez promueve determinados estilos de aprendizaje, Greenfield (2008); ésta afirmación sitúa a YouTube como una poderosa herramienta educativa, gracias a sus características de uso que permiten al usuario particular ser creador de su propio contenido y retransmisor del contenido creado por otros.

Todo esto que describe a YouTube y que ha ido conformando su historia desde su lanzamiento en 2005 nos interesa en términos generales al examinar la participación de la tecnología y los medios sociales de internet de la manera cómo ha ido evolucionado la comunicación hacia el usuario por parte de marcas, empresas e instituciones, así como también, su papel en la comunicación cultural actual, siendo éste nuestro campo de estudio e interés profesional.

\section{Perspectivas}

\section{YouTube como medio de comunicación de la nueva era y elemento clave en la comunicación de marcas, empresas e instituciones}

Desde que aparecieron las primeras plataformas de video en línea, mucho se ha especulado sobre los cambios que estos impulsarían en la industria del entretenimiento y la comunicación de masas, sin embargo, la predicción de que YouTube y medios similares remplazarían la televisión es ya cosa del pasado; YouTube no es televisión, representa un nuevo y revolucionario medio, uno participativo y democrático, una ruptura en el modelo tradicional de negocios de los medios y el nacimiento de un nuevo poder (Gehl, 2009; Burgess y Green, 2009). Lo cierto es que YouTube como medio es absolutamente revolucionario, no es una emisora, o un medio de comunicación manejado por el gobierno o el sector privado, en YouTube cualquier usuario convencional puede subir un video y esto le convierte en un medio de comunicación totalmente democrático. 
Otra de las características que refleja esta democratización es la libre selección de los contenidos que el usuario desea consumir, de hecho, YouTube marca y distingue claramente algunos videos con etiquetas como "vistos ahora mismo" o "video promocional" y el consumidor puede elegir si visualizar o no estos videos destacados con pleno conocimiento y consciencia del motivo por el cual aparecen destacados en el portal.

YouTube es la mejor ejemplificación del ambiente que han credo los medios sociales de internet, un ambiente en el que cualquiera puede hacer las dos funciones; consumidor y proveedor (Haridakis y Hanson, 2009), por ello, tal y como se aprecia en otros medios sociales de internet, las empresas deben crear estrategias específicas para darse a conocer en este medio conforme a la naturaleza democrática del mismo. Tomemos en cuenta que YouTube aloja una gran cantidad de contenidos, y mientras algunos trascienden la brecha viral y llegan a ser incluso compartidos en redes sociales, otros pasan prácticamente desapercibidos. No es nada sencillo, por tanto, destacar en YouTube (Lavado, 2010).

YouTube es una herramienta interesante para las empresas a nivel de comunicación, pero para conseguir el éxito con ella han de conocerla a fondo, además, la popularidad que consigue alcanzar un contenido en este nuevo medio no responderá únicamente a razones estéticas, y por tanto es más complicado predecir un resultado exitoso conforme a estos términos, como enfatizan Zink et al. (2009), en los servicios VoD, «Video bajo Demanda», la calidad de producción de los video está relativamente controlada y esto de cierta manera permite controlar también la popularidad de los mismos, en cambio en YouTube no es así, cualquiera puede subir un video a YouTube, por tanto la calidad de estos videos varía y en consecuencia el predecir cuál será su popularidad.

YouTube ha publicado su propia lista de recomendaciones para conseguir el objetivo de «enganchar» al espectador, tomando como punto de partida el hecho de que es en los primeros segundos de reproducción del video cuando el espectador toma la decisión de si seguirá visualizándolo o no. Algunas de las recomendaciones más destacadas de YouTube (2014) para las empresas son: dirigirse a la audiencia de inmediato, describir durante los primeros segundos lo que va a verse en el video, decir cosas que despierten la curiosidad, o incluso partir desde una o varias preguntas.

El portal es utilizado por las empresas como una herramienta de marketing potente, de hecho, Google Inc., empresa propietaria de YouTube en la actualidad, ha publicado: «Grow your business with YouTube a step-by-step guide» (YouTube, 2012) una guía de uso para el marketing, en la que se clasifican los tres tipos de videos publicitarios que funcionan de forma óptima en la plataforma; informativos, educativos y de venta.

Red Bull y GoPro son dos marcas que han logrado resultados sorprendentes en el uso de YouTube como parte de su comunicación y herramienta clave para la ejecución de su estrategia de marketing de contenidos (Swallow, 2012; Ratcliff, 2014), el punto fuerte de su comunicación en línea es el video, pero además, ambas sobresalen positivamente en redes sociales como Facebook, Twitter o Instagram.

Otras marcas con una sobresaliente estrategia de comunicación y participación en YouTube, tanto por su trayectoria como por sus resultados durante el presente año 2014 son: Fiat, PlayStation, Home Depot y Pepsi (Houghteling, 2014), todas se distinguen por la originalidad del contenido que publican en sus respectivos canales de YouTube y a la vez por conseguir que este contenido sea relevante a su público objetivo.

\section{Uso de YouTube en la comunicación cultural y de los museos}

Nuestra base de interés para realizar este análisis de YouTube y su uso, es identificar y reconocer cómo lo han aprovechado las instituciones culturales para integrarlo como herramienta de comunicación con los públicos, partiendo sobre todo de la efectividad comprobada del portal de videos al momento de promocionar bienes de consumo.

El fenómeno de la comunicación participativa que ha traído consigo la web 2.0 no se limita sólo al contexto de los negocios. Los museos y otras las instituciones culturales dependen cada vez más de estos medios de comunicación social para cumplir sus objetivos (Pallud, 2014), pues, aunque la comunicación cultural tiene sus características particulares, busca las fórmulas para integrarse con sus públicos en espacios ajenos a la estructura museística, siendo el de mayor interés reciente su espacio virtual en internet. 
Según la definición oficial del ICOM, Consejo Internacional de los Museos, un museo es "una institución permanente, sin fines de lucro, al servicio de la sociedad y abierta al público" (ICOM, 2012), partiendo de este punto, se hace lógico que los museos en lo que se refiere a la comunicación con los públicos vayan a ritmo del lenguaje actual de la sociedad a la que pretenden servir, por tanto, entendemos, es vital la integración, conocimiento y adaptación a fenómenos sociales como los de las nuevas redes de la Web 2.0.

YouTube se integra a la perfección en los museos no sólo como herramienta de comunicación, sino además, como elemento de archivo y consulta. Para Gehl (2009) la propia estructura de YouTube lo convierte en una especie de «Wunderkammer», una caja de maravillas, sosteniendo la idea de YouTube como un gran archivo que debe ser aprovechado como tal.

En YouTube puede ser más atractivo un contenido creado por los usuarios que el creado por el propio museo (Bernstein apud. Kidd ,2011), esto amplía las posibilidades para la comunicación cultural y la diversidad de acciones que puede ejecutar un museo o institución cultural a partir de esta premisa. Capacitar a las personas para crear y compartir sus narraciones fomenta una mayor participación en la comunidad del museo y ayuda a que los profesionales de los museos puedan continuar creativamente su trabajo (Greenfield, 2008), es decir, si vemos a YouTube como una herramienta para la construcción de narrativas personales a partir de relatos de la experiencia del usuario estamos ante la posibilidad de crear, en nuestra opinión profesional, un gran archivo de experiencias en estas instituciones, experiencias que sean una invitación en movimiento para conocer las piezas y obras que se exhiben en las instituciones.

Estamos de acuerdo con la afirmación que hiciera el año pasado la Red Canadiense de Información del Patrimonio (2013) tras integrarse la mayor parte de los museos de la red a YouTube, cuando confirmaba a YouTube como una magnífica herramienta para los museos pequeños.

Hay diversos ejemplos de museos actuales que se han apoyado en YouTube como herramienta museística y de contacto con el público, uno que nos parece muy interesante es el caso del Museo de Arte Moderno de Nueva York (MoMA) que presentó en 2006 una experiencia en colaboración con «The Residents ${ }^{1}$ » un grupo musical y de artes visuales de sonada trayectoria, la experiencia partía de una serie de videos basados en imágenes y un audio creados por el grupo que se publicaron en YouTube en una especie de exposición virtual donde la usuarios seleccionaban los mejores videos a través de opiniones y votaciones (Lavallee, 2006), el proyecto se llamó «River of Crime Community Art Project», y en cierta medida los usuarios ejercían como curadores para la muestra.

El Museo de Arte Contemporáneo de Los Ángeles (MOCA) presentó en 2013 la campaña «Art is

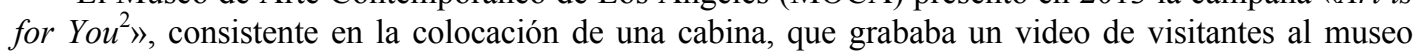
mientras contestaban preguntas relacionadas con su experiencia con el arte contemporáneo, por ejemplo «¿Qué es para ti el arte contemporáneo?», el video se grababa en la propia cabina y se empezaba a rodar a partir del momento en que los visitantes tocaban la pantalla de la misma, siguiendo una indicación sencilla, el objetivo principal era captar a la audiencia que participa activamente en la cultura visual contemporánea hoy en día (The Museum of Contemporary Art, Los Ángeles, 2013).

\section{Contribución y conclusiones}

\section{Propuesta de recomendaciones del uso de YouTube basadas en su uso por parte de museos de gran envergadura extrapolables a Pequeñas Instituciones Culturales}

Nos ha parecido interesante enumerar en forma de contribuciones las conclusiones de nuestro análisis y que a la vez puedan convertirse en una única propuesta de recomendaciones extrapolables a Pequeñas Instituciones Culturales.

Tras repasar nuestro estudio y análisis de diversos escritos y artículos relacionados con YouTube, así como también los perfiles de algunos de los museos de mayor envergadura a nivel mundial y teniendo como base nuestra propia relación profesional e investigativa con el tema de la comunicación museística, presentamos la siguiente propuesta con miras a que estas recomendaciones puedan

\footnotetext{
${ }^{1}$ Accesible en The Residents - MoMA: https://www.youtube.com/user/theresidentsmoma

${ }^{2}$ Art is for You - MOCAtv https://www.youtube.com/watch?v=RyevOfU838s
} 
ser tomadas como punto de partida para la mejora de la comunicación a través de herramientas como YouTube o similares.

Al visitar los canales de YouTube de algunos museos de gran envergadura que mantienen una estrategia definida en redes sociales: Museo de Arte Moderno de Nueva York, MoMA: [www.YouTube.com/MoMAvideos], el Museo de Arte Contemporáneo de Los Ángeles, MOCA: [www.YouTube.com/MOCATV], Museo de Arte Metropolitano de Nueva York: [www.YouTube.com/metmuseum ], se distingue que estos museos de arte moderno y contemporáneo son instituciones que por la temática de sus colecciones pueden encajar herramientas modernas obteniendo de estas el máximo provecho, otros museos de arte clásico como el Museo del Louvre y el Museo Británico de Londres también han incorporado el video online como medio adicional de comunicación, pero desde una perspectiva distinta y más acorde a sus respectivas líneas de comunicación, por ejemplo, el Museo Británico posee un canal específico con videos incrustados en la propia página web del museo (Patronato del Museo Británico, 2014), estos videos pueden compartirse en redes sociales pero no se encuentran oficialmente publicados en ninguna. A todo esto podríamos afirmar que son los museos de temáticas contemporáneas los que presentan un mayor interés en poseer un canal específico en YouTube.

Para el presente análisis, también hemos considerado algunos museos de España, país en el cual practicamos nuestra labor investigadora. Para los españoles, YouTube es la plataforma de video online más conocida y también la más utilizada (IAB, 2014), por ello es que también nos ha resultado interesante observar los perfiles de las instituciones museísticas españolas que participan activamente en YouTube como son el Museo de Arte Contemporáneo de Barcelona, MACBA: [www.YouTube.com/ MACBAwebmaster]; Museo Guggenheim de Bilbao: [www.YouTube.com/ guggenheimbilbao2009] y el Museo del Prado: [www.YouTube.com/museodelprado], este último es un buen ejemplo de museo de arte clásico que se ha integrado a YouTube manejando sus propios lenguajes.

A partir de las características y estrategias más interesantes usadas por estos museos en sus respectivos Canales de YouTube, planteamos la siguiente lista de recomendaciones de uso de YouTube dirigidas a museos e instituciones culturales de menor envergadura y/o carácter local:

Entrevistas: un recurso interesante que encontramos en varios de los canales de YouTube a los que hacemos referencia son las entrevistas, museos como el MOMA, o el Museo del Prado, utilizan las entrevistas como contenido audiovisual habitual; el Museo del Prado tiene, por ejemplo, una serie de videos llamada «Otros ojos para ver el Prado $^{3} »$, donde los conservadores del museo exponen detalles acerca de las obras más emblemáticas de éste. Por otro lado, tenemos a los artistas, el canal de YouTube del MACBA presenta una lista de reproducción denominada «Fons de documentació audiovisual ${ }^{4} \gg$, donde son los propios artistas contemporáneos quienes comentan su proceso creativo. Consideramos que una institución de menor tamaño y con menos recursos podría también integrar las entrevistas en su canal de YouTube presentando a artistas, curadores, museógrafos u otros intervinientes de su acción cultural, además, no necesitaría de grandes y costosos recursos para producirlas.

Video-Presentaciones: una presentación en video de una muestra o exposición, es también un recurso práctico para presentar las actividades futuras o actuales del museo, y el nivel de producción podría adaptarse al nivel de presupuesto de la institución. Una de las ventajas que apreciamos en este recurso en particular es que una presentación en formato video de una actividad es algo que los usuarios se interesarían en compartir con otros usuarios, el Museo Guggenheim Bilbao publica una video-presentación de cada exposición nueva, como ejemplo de la repercusión que consigue una publicación de estas características nos encontramos con el video «El arte de nuestro tiempo. Obras maestras de las Colecciones Guggenheim», este video consiguió 321.791 visualizaciones en las primeras tres semanas de su publicación en el canal de YouTube del museo. Nuestra recomenda-

\footnotetext{
${ }^{3}$ Otros ojos para ver el Prado. Introducción. Accesible en: http://www.youtube.com/watch?v=RdMUZczL83Y\&list= PL29B276D7FEED7241

${ }^{4}$ Fons de documentació audiovisual, accesible en: https://www.youtube.com/playlist?list=PLBC9244AB40164A40
} 
ción para una institución que no disponga de los recursos audiovisuales de los que disponen los grandes museos, es optar por un video de producción simple basado en imágenes y textos.

Documentar los procesos: pueden presentarse imágenes al público del montaje de la exposición o la restauración de una pieza; algo interesante presenta en su canal de YouTube el Museo de Arte Metropolitano de Nueva York donde se han publican series de videos que explican paso a paso el proceso de la restauración de una pieza de mano de los propios restauradores «The Conservation of Tullio Lombardo's Adam ${ }^{5} »$, es el ejemplo mas reciente de este tipo de práctica que es a nuestro parecer un recurso social de interés para las instituciones que poseen su propio departamento de restauración, conservación o archivo.

Listas de reproducción temáticas: una acción que han llevado a cabo algunos museos, como ejemplo el MOCA, es incluir listas temáticas para distribuir sus contenidos de una manera que resulta más atractiva para el usuario, el MOCA incluye en su canal listas que relacionan al arte contemporáneo con otras manifestaciones, apoyándose en nombres como «art + music», arte y música o «art + comedy», arte y comedia.

Varios canales: un museo pude tener más de un canal oficial en YouTube, manteniendo un canal principal y otros tantos que abarquen otras temáticas, como en el caso del Smithsonian que posee un listado con más de 30 canales de YouTube del propio Smithsonian e instituciones relacionadas (Smithsonian, 2014).

Conexión a internet wi-fi gratuita: consideramos que la posibilidad de conectarse gratuitamente a internet desde las instalaciones y salas de exposiciones facilitará a los usuarios compartir al momento su experiencia en las instalaciones.

Otras redes: todos los museos que hemos observado poseen presencia activa en otras redes en las cuales hacen uso del mismo tono de comunicación y lenguaje estético que en su canal de YouTube, algunos canales poseen incluso enlaces a las otras redes y viceversa.

Todas estas recomendaciones que exponemos parten de elementos que han funcionado o están funcionando actualmente en la comunicación de los grandes museos del mundo y que pueden representar para otros museos e instituciones culturales un giro interesante en la búsqueda de la interacción y el acercamiento a los públicos.

\footnotetext{
5 After the Fall: The Conservation of Tullio Lombardo's "Adam": http://www.youtube.com/watch?v=3oznnP6SkSc\&list= PL8HAkqKX065DK2y0T3LGvOPICYtkMmpHv
} 


\section{REFERENCIAS}

Baluja, S., Seth, R., Sivakumar, D., Jing, Y., Yagnik, J., Kumar, S., Ravichandran, D., Aly, M. (2008). Video Suggestion and Discovery for YouTube: Taking Random Walks Through the View Graph. Proceeding of the 17th international conference on World Wide Web (pp. 895-904). New York: ACM.

Burgess, J. y Green, J. (2009). YouTube: Online Video and Participatory Culture. Estados Unidos de América: Polity Press

Camacho, J. y Jorge Alonso, A. (2010). La baja interacción del espectador de videos en Internet: caso YouTube España. Revista Latina de Comunicación Social, 65, pp. 421-435. Recuperado en http://www.revistalatinacs.org/10/art3/910_Malaga/32_Gallardo.html

Cheng, X.; Dale, C. y Liu, J. (2007). Understanding the Characteristics of Internet Short Video Sharing: YouTube as a Case Study. Cornell University Library. Consultado 110 de noviembre de 2014 en http://arxiv.org/abs/0707.3670v1

Davidson, J., Liebald, B., Liu, J., Nandy, P. y Van Vleet, T. (2010). The YouTube Video Recommendation System. Proceedings of the fourth ACM conference on Recommender systems (pp. 293-296). New York: ACM.

El País. (2006). Google compra la web YouTube por 1.300 millones. [tecnologia.elpais.com] consultado el día 17 de noviembre de 2014 en: http:/tecnologia.elpais.com/tecnologia/2006/ 10/10/actualidad/1160468878 850215.html

Gehl, R. (2009). YouTube as archive: Who will curate this digital Wunderkammer? International Journal of Cultural Studies 2009, 12, p. 43.

Greenfield, D., YouTube To MuseTube - Now We Have Web 2.0 Tools, How Do We Use Them? in J. Trant and D. Bearman (eds.). Museums and the Web 2008: Proceedings, Toronto: Archives \& Museum Informatics. Published March 31, 2008. Consulted November 14, 2014. http://www.archimuse.com/mw2008/papers/ greenfield/greenfield.html

Haridakis, P. y Hanson, G. (2009). Social Interaction and Co-Viewing with YouTube: Blending Mass Communication Reception and Social Connection. Journal of Broadcasting \& Electronic Media, 54(02), pp. 317-335.

Houghteling, N. (2014). 5 Brands to Emulate on YouTube. [mashable.com], consultado el 10 de noviembre de 2014 en http://mashable.com/2014/05/29/YouTube-brand-content/

IAB Spain. (2014). II Estudio Anual IAB Spain TV Conectada y Vídeo Online. [iabspain.net] consultado 110 de noviembre de 2014 en: http://www.iabspain.net/investigacion/

ICOM. (2012). Definición del Museo. [icom.museum]. consultado el día 17 de noviembre de 2014 en: http://icom.museum/la-vision/definicion-del-museo/L/1/

Kidd, J. 2011. Enacting Engagement Online: Framing social media use for the Museum. Information, Technology and People, 24(1), pp. 64-77.

Lange, P. (2008). Publicly Private and Privately Public: Social Networking on YouTube. Journal of Computer-Mediated Communication, 13(2008), pp. 361-380.

Lavado, A. (2010). El consumo de YouTube en España. Global Media Journal México, 7(14), pp. 76-92.

Lavallee, A. (2006). Museums try YouTube, Flickr to find new works for the walls. The Wall Street Journal Online. [online.wsj.com]. Consultado el 13 de octubre de 2014 en: http://online.wsj.com/article_email/article_print/SB1160405434140868911MyQjAxMDE2NjEwMzQxMDM1Wj.html

Pallud, J. (2014). How Web 2.0 Tools Impact The Museum-Visitor Relationship. Kit Scientific Publishing, 01(01), pp. 91-101.

Patronato del Museo Británico. (2014). The British Museum Channel. [britishmuseum.org] consultado el día 23 de octubre de 2014 en: http://www.britishmuseum.org/channel.aspx

Polo Serrano, D. (2010). La popularización del vídeo en internet. Del videoclub a YouTube en HTML-5. Razón y Palabra, 15. Consultado el 22 de noviembre de 2014, URL: en: http://www.redalyc.org/articulo.oa?id=199514906032 
Ratcliff, C. (2014). Red Bull vs GoPro: taking content marketing to the extreme. [econsultancy.com]. Consultado el día 13 de octubre de 2014 en: https://econsultancy.com/blog/ 65416-red-bull-vs-gopro-taking-content-marketing-to-the-extreme

Red Canadiense de Información del Patrimonio. (2013). Resources for Social Media in Museums. [rcip-chin.gc.ca] Consultado el 16 de septiembre de 2014 en: http://www.rcipchin.gc.ca/sgc-cms/nouvelles-news/anglais-english/?p=7094

Renó, D. (2007). YouTube, el mediador de la cultura puar en el ciberespacio. Revista Latina de Comunicación Social, 62. Recuperado el 11 de noviembre de 2014 de: http://www.ull.es/publicaciones/latina/200717Denis_Reno.htm

Smithsonian. (2014). Smithsonian Channels. [si.edu] consultado el 20 de octubre d 2014 en: http://www.si.edu/Connect/YouTube\#SocialMedia

Swallow, E. (2012). How Red Bull's Content Strategy Got Its Wings. [contently.com]. consultado el 13 de septiembre de 2014 en: http://contently.com/strategist/2012/01/24/red-bull-media-house/

The Museum of Contemporary Art, Los Angeles. (2013). Art is for you. [moca.org/artisforyou]. Consultado el 12 de octubre de 2014 en: http://sites.moca.org/artisforyou/

YouTube. (2012). Grow your business with YouTube. A Step-by-Step Guide. [static.googleusercontent.com]. Consultado el 10 de noviembre de 2014 en http://static.googleusercontent.com/media/www.YouTube.com/es//yt/advertise/medias/pdfs /advertiser-playbook-en.pdf

- (2014). Acerca de YouTube. [YouTube.com] consultado el día 17 de noviembre de 2014 en: https://www.YouTube.com/yt/about/es/

- (2014). Estadísticas. [YouTube.com] consultado el día 17 de noviembre de 2014 en: https://www.YouTube. com/yt/press/es/statistics.html

Zink, M., Suh, K., Gu, Y. y Kurose, J. (2009). Characteristics of YouTube network traffic at a campus network - Measurements, models and implications. Computer Networks, 53, pp. 501- 504.

\section{SOBRE LA AUTORA}

Georgina Marcelino Mercedes: Georgina Marcelino es Licenciada en Publicidad por la Universidad Autónoma de Santo Domingo (República Dominicana) y Máster en Publicidad de la Universidad Antonio de Nebrija (España). Actualmente, elabora una tesis doctoral en Publicidad y Relaciones Públicas en la Universidad Camilo José Cela (España) donde investiga sobre gestión cultural y comunicación en medios digitales. Es Artista Visual por la Escuela Nacional de Artes Visuales de República Dominicana y Creativo-fundadora en la agencia de publicidad Green Thinking. 